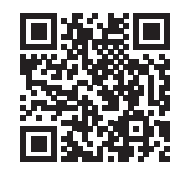

\title{
Under Our Eye: Margaret Atwood's Variation on the Panopticon in The Heart Goes Last
}

\begin{abstract}
In her dystopian dark comedy The Heart Goes Last (2015), Margaret Atwood openly refers to Jeremy Bentham's concept of the Panopticon. The future world depicted in her novel is filled with violence and deprived of both human bonds and hope. Hence, being contained, monitored and - after Foucault - disciplined and punished appears to be the characters' last resort. Surveillance tempts both sexes as it is politically correct and universal, and it does not privilege one group of people over the other.

The article discusses the dystopian vision of the near future as created by Atwood in her 2015 novel, with direct references to the conception of the Panopticon, both in its original meaning proposed by Bentham, and - more significantly - in Michel Foucault's reading of this idea as a metaphor of the way western societies are organized.
\end{abstract}


* Institute of Literature Sciences, University of Opole pl. Kopernika 11, 45-040 Opole e-mail:slavekkk@wp.pl 


\section{Under our eye: Margaret Atwood's variation on the Panopticon in The Heart Goes Last}

Musing on the idea of a perfect penitentiary system, Jeremy Bentham states: “... the more constantly the persons to be inspected are under the eyes of the persons who should inspect them, the more perfectly will the purpose $\mathrm{X}$ of the establishment have been attained. Ideal perfection, if that were the object, would require that each person should actually be in that predicament, during every instant of time" (1995: 5). The Panopticon is the realization of his goals, and also the concept that decades later Margaret Atwood refers to in her dystopian dark comedy The Heart Goes Last (2015). Commenting on the origins of the novel, she states: "I think we need to rethink prisons" (qtd. in Keeler 2015). However, this declaration of hers can serve as a symbolic representation of the whole contemporary western culture in which people are constantly monitored and deprived of their freedoms. The $21^{\text {st }}$-century, high-tech and almost invisible surveillance is unisex: it tempts everyone as it is politically correct and universal, and it does not privilege one group of people over the other. It is also sexy as it enables survival in Atwood's vision of the near future where the world is filled with violence and deprived of both human bonds and hope. Hence, Atwood's variant of the Panopticon may be summarized as utopia turning dystopia.

\section{Post 2008 venture}

Published as a book in 2015, The Heart Goes Last originated from a series of four episodes that Margaret Atwood published in an e-book format via The Byliner startup between the spring of 2012 and May 2013. This formula required from the author a new approach to the way she usually works: “... she got absorbed in the story and was intrigued by the process of shaping a narrative in full view of the public, building in cliffhangers and plot twists to keep readers coming back. She described it as a high-tech version of $19^{\text {th }}$-century serialized works like Dickens's The Pickwick Papers" (Alter 2015). Only then was the decision made to rewrite the already published installments into a full-length novel, which some critics view as the reason for the book's uneven quality (Lyall 2015). It also resulted in a book whose genre is very difficult to determine. M. John Harrison notes: "At first a classic Atwood dystopia, rationally imagined and developed, it relaxes suddenly into a kind of surrealist adventure... [It is] jubi- 
lant comedy of errors, bizarre bedroom farce, SF prison-break thriller, psychedelic 60 s crime caper" (2015). One can also perceive The Heart Goes Last as a sex comedy of manners situated in the post-apocalyptic reality with some seemingly Shakespearean undertones - something that Atwood was simultaneously developing in her reworking of The Tempest published under the title Hag-Seed (2016). Most importantly, however, despite its dominating lighthearted tone, The Heart Goes Last is a novel that touches upon the serious issues of personal freedom and free will in the world of exhaustion.

The background of the novel is the world of a very near future after a "catastrophic economic collapse" (Lyall 2015). Hence, this time Atwood's dystopia dwells upon the 2008 financial crisis rather than some kind of ecological catastrophe or biological pandemic, as it was in her MaddAddam trilogy. Similarly to these novels, nonetheless, The Heart Goes Last depicts the capitalistic and consumerist world in the last phase of its existence: "It's the near future, and finance capitalism has pushed itself over the edge" (Harrison 2015). The world of the novel is no longer safe and civilized: "There's no safe place, there are no instructions. It's like he's being blown by a vicious but mindless wind, aimlessly round and round in circles. No way out" (Atwood 2015a: 4). It is the world in which the back-to-primitive scenario is being realized, where all the institutions of social care have collapsed, and people have lost the ground beneath their feet. And all that happened as if it was all of a sudden:

\footnotetext{
Then everything went to ratshit. Overnight, it felt like. Not just in his own personal life: the whole card castle, the whole system fell to pieces, trillions of dollars wiped off the balance sheets like fog off a window. There were hordes of two-bit experts on TV pretending to explain why it had happened - demographics, loss of confidence, gigantic Ponzi schemes - but that was all guesswork bullshit. Someone had lied, someone had cheated, someone had shorted the market, someone had inflated the currency. Not enough jobs, too many people. (Atwood 2015a: 7)
}

In such dark times when large parts of the world dive into anarchy and chaos - Atwood warns her readers - it is very easy to forget about the most fundamental liberties, and focus only on mere survival. Forced to choose between personal freedom and a steady employment, the desperate ones decide on the latter. Keeping the familiarly bearable standards of life, people abandon their identities, and prisons of Atwood's near future are the beneficiaries of this situation.

\section{Utopia turning dystopia}

Atwood's Consilience/Positron project envisioned in The Heart Goes Last serves as a peculiar combination of dystopia with utopia: a state-of-the-art corporation with a hint of nostalgia for the good old days. The management of the institution advertises it using such metaphorical words:

Their new home, right here inside Consilience. And inside Positron, of course. Think of an egg, with a white and a yolk. (An egg came up onscreen, a knife cut it in half, lengthwise.) Consilience is the white, Positron is the yolk, and together they make the whole egg. (Atwood 2015a: 42)

Consequently, the whole system is founded on a peculiar duality of hypothetical freedom and official imprisonment: 
In brief, everyone in Consilience will live two lives: prisoners one month, guards or town functionaries the next. Everyone has been assigned an Alternate. One detached residential dwelling can therefore serve at least four people: in Month One, the houses will be occupied by the civilians, and then, in Month Two, by the prisoners of Month One, who will take on the civilian roles and move into the houses. And so it will go, month after month, turn and turn about. (Atwood 2015a: 42)

In other words, one may view Consilience as a giant prison system composed of residents who share their time between playing the role of real inmates (i.e. living in a confined and controlled community), and free citizens who take care of the very prison. Additionally, organized on the premises of a civilian town Consilience, the project does not attempt to hide its economic goal, at the same time emphasizing the feeling of safety and comfort it provides for its participants. Such politics is deeply rooted in Bentham's philosophy:

The turning of the prisoners' labour into the most profitable channels being left free, depending upon the joint choice of the two only parties interested in pushing the advantage to the utmost, would afford a resource, and that I should conceive a sure one, for the subsistence of the prisoners, after the expiration of their terms. (1995: 29)

What is more, the frequency of Positron's advertisement "CONSILIENCE $=$ CONS + RESILIENCE. DO TIME NOW, BUY TIME FOR OUR FUTURE!” (Atwood 2015a: 41) parallels the ubiquity of the slogan "BIG BROTHER IS WATCHING YOU” from George Orwell's 1984 (1987: 3). Mat Johnson notes: "The Positron Project is an attempt to remedy this, a utopian solution for a dystopian world. If prisons are a surefire way to make money, why not create a town that thrives because its residents serve as its prisoners?" (2015). Consequently, Bentham's utilitarian ideas are also visible in the economic mechanisms applied to the project, with the focus of the profits that such a venture should generate.

Furthermore, the utopian dimension of Atwood's project does not only provide its participants with the material assets (tidy and spacious homes, ${ }^{1}$ excellent food, etc.), but - in contrast to the unstable reality outside Consilience walls - it also offers a world without violence and constant threat. The advertisement that is supposed to lure people trying to endure the difficult economic and social conditions of the quasi-dystopian America says:

The Consilience/Positron twin city is an experiment. An ultra, ultra important experiment; the think-tankers use the word ultra at least ten times. If it succeeds - and it has to succeed, and it can succeed if they all work together - it could be the salvation, not only of the many regions that have been so hard-hit in recent times but eventually, if this model comes to be adopted at the highest levels, of the nation as a whole. Unemployment and crime solved in one fell swoop, with a new life for all those concerned — think about that! (Atwood 2015a: 37)

Referring to the brutality-driven and completely uncertain reality that makes life unsafe and almost unbearable, Atwood creates the vision of futuristic, heaven-like Positron that offers its participants stability, safety, and comfort. At the same time, to make this place look even

$1 \quad$ “Then a house, a neat, freshly painted house with a hedge and a lawn, no junked cars or wrecked sofas lying on it, and then the camera zooms in through the second-floor window, past the curtains — curtains! - and moves through the room. Spacious! Gracious!” (Atwood 2015a: 25). 
more utopian, the number of actual criminals is gradually reduced to zero as criminals could jeopardize the whole project. The prison does not want surprises; instead it wants to be predictable.

Additionally, the whole prison appears to be a mock theme park with the focus on the 1950s: "The fifties was chosen for the visual and audio aspects, because that was the decade in which the most people had self-identified as being happy. Which is one of the goals here: maximum possible happiness" (Atwood 2015a: 41). The intention is to dispose of all unnecessarily disturbing references to the brutal present and focus on its aesthetic quality. Consequently, one can sense the novel's "vibe of the 1950s sitcom" (Keeler 2015). At the same time, however, the choice of the decade seems deliberate: it reinforces in the inmates the feeling of "its postwar embrace of quiet order" (Johnson 2015). Also, the idea that Positron lacks criminals appears to be the realization of the concept of a perfect community living in peace and harmony. However, under such circumstances it is very easy to blur the line between free choice and punishment. The narrator of the novel notes:

Considering that the whole point of Consilience is for things to run smoothly, with happy citizens, or are they inmates? Both, to be honest. Because citizens were always a bit like inmates and inmates were always a bit like citizens, so Consilience and Positron have only made it official. (Atwood 2015a: 145)

This problematizes the utopian image with all its consequences.

The penitentiary system of The Heart Goes Last has been inspired by the moral ambivalence behind the contemporary American private-owned prisons whose main focus lies in economic self-sufficiency. Atwood states: "For-profit prisons are never a good idea, because to keep them profitable you have to keep having more prisoners" (qtd. in Alter 2015). Consequently, her sharpest criticism of Positron prison - as well as the political and civilizational trends it symbolizes - concerns the hypocritical imbalance between providing the inmates with material comfort, and depriving them of various freedoms. After all, as one of the most important rules of Positron states: "...you were either out or you were in. In was permanent. But no one would force you. If you signed up, it would be of your own free will" (Atwood 2015a: 33). Consequently, she focuses on the idea of the Panopticon as the most graphic example of these tendencies.

\section{Under their eye}

The assumptions of the Panopticon are straight, simple and commonly known. The idea that appeared in Jeremy Bentham's mind in the late $18^{\text {th }}$ century can be summarized by its founder's following words: "The essence of it consists, then, in the centrality of the inspector's situation, combined with the well-known and most effectual contrivances for seeing without being seen" (1995: 12). Michel Foucault adds:

The panoptic mechanism arranges spatial unities that make it possible to see constantly and to recognize immediately. In short, it reverses the principle of the dungeon; or rather of its three functions - to enclose, to deprive of light and to hide - it preserves only the first and eliminates the other two. Full lighting and the eye of a supervisor capture better than darkness, which ultimately protected. Visibility is a trap. (1995: 200) 
In both interpretations, these are the ideas of thorough monitoring and total surveillance that constitute the foundations of this project: an individual - no matter if they are prisoners or ordinary citizens - should know that they are constantly watched, although they do not know whether it actually happens at a particular time. The Panopticon, then, turns an individual's personal freedom into a peculiar kind of self-custody: it is one's consciousness that becomes their most inescapable prison. Foucault notes: "Hence the major effect of the Panopticon: to induce in the inmate a state of conscious and permanent visibility that assures the automatic functioning of power" (1995: 201).

Writing about the long history of penitentiary systems, as well as their actual meanings for the western civilization, Michel Foucault notes:

In short, the art of punishing, in the regime of disciplinary power, is aimed neither at expiation, nor even precisely at repression. It brings five quite distinct operations into play: it refers individual actions to a whole that is at once a field of comparison, a space of differentiation and the principle of a rule to be followed. It differentiates individuals from one another, in terms of the following overall rule: that the rule be made to function as a minimal threshold, as an average to be respected or as an optimum towards which one must move. It measures in quantitative terms and hierarchizes in terms of value the abilities, the level, the "nature" of individuals. It introduces, through this "value-giving" measure, the constraint of a conformity that must be achieved. Lastly, it traces the limit that will define difference in relation to all other differences, the external frontier of the abnormal... The perpetual penality that traverses all points and supervises every instant in the disciplinary institutions compares, differentiates, hierarchizes, homogenizes, excludes. In short, it normalizes. (1995: 182-183)

Indeed, normalization is the procedure that we can observe in Atwood's Positron. Very soon what might have appeared as the dream-come-true situation for those who have chosen to live inside the prison-non-prison institution, slowly but steadily drifts into a dystopian system of economic exploitation and depravation of all liberties. The management inform their inmates:

Positron Prison has been chosen for a vital role in that solution. Every resident of Consilience will have a part to play, if only by keeping out of harm's way and being alert to subversion from within, but for the present they can best help by simply going about their daily routine as if nothing unusual is happening, despite the unavoidable disruptions that may occur in that routine from time to time. (Atwood 2015a: 118-119)

The management, which serves here as the Atwoodian version of the totalitarian state in miniature, cannot afford risk and uncertainty when it comes to their politics and economics. They soon realize that to safeguard the project as productive as possible and as impervious to the external influence, total control of the inmates has to be launched in Positron. Therefore,

[t] he whole town is under a bell jar: communications can be exchanged inside it, but no words get in or out except through approved gateways. No whines, no complaints, no tattling, no whistleblowing. The overall message must be tightly controlled: the outside world must be assured that the Consilience/Positron twin city project is working. (Atwood 2015a: 51). 
This is the point where high-tech surveillance meets painstakingly supervised propaganda. If the project is to be regarded successful, fortuity of its public reception has to be reduced to zero. Hence, it is the artificially implemented politics of success that constitutes the core of Positron.

\section{A human body}

One of the most visible signs of dystopian politics as realized by the Positron management is the urge to discard the potentially threatening elements. At first, these are the real criminals who also participate in the project as a kind of rehabilitating experiment. The place starts to be governed in a more and more oppressive way, and, as a result, the dangerous elements disappear:

After surveillance was tightened, the worst troublemakers vanished. Consilience was a closed system — once inside, nobody went out — so where had they gone? "Transferred to another wing" was the official version. Or else "health problems." Rumours as to their actual fates began to circulate, in furtive hints and nods. Behaviour improved dramatically. (Atwood 2015a: 64-65)

The politics of Positron is efficient and direct, yet discreet. Its authorities seem aware of the fact that to maintain order a dosage of clever manipulation is necessary. At the same time, it soon appears that the management is capable of absolutely anything to maintain its omnipresent and omnipotent position, although everything they do, they do under the veil of state-of-the-art humanitarianism. The method is called Special Procedure.

Special Procedure is the vague and innocent name of the unofficial but entirely legal execution performed on potentially dangerous individuals, including the aforementioned real criminals. In Atwood's novel it is the female protagonist, Charmaine, a rather naïve and passive character, who specializes in it. And although technically speaking the whole procedure is legalized killing, the Positron management makes it look as humanized, just, and even desirable as possible. Hence, even Charmaine seems to be persuaded into believing there is nothing wrong with it. She thinks:

Granted, it's only the worst criminals, the incorrigibles, the ones they haven't been able to turn around, who are brought in for the Procedure. The troublemakers, the ones who'd ruin Consilience if they had the chance. It's a last resort. They'd reassured her a lot about that. (Atwood 2015a: 69)

In a way, she becomes a caricature of an executioner figure always present in the history of humankind that Foucault characterizes in the following way: "The executioner not only implemented the law, he also deployed the force; he was the agent of a violence applied, in order to master it, to the violence of the crime. Materially, physically, he was the adversary of this crime: an adversary who could show pity or ruthlessness" (1995: 51). Although Charmaine acts here rather as a puppet cleverly manipulated by the puppeteer - not an active agent of violence - she is definitely capable of showing pity and ruthlessness at the same time. She kills, hence exercising her power on the executed - no matter how illusionary this power actually is - but she is also full of compassion: 
She leans over, kisses this man on the forehead... She strokes the man's head, smiles with her deceptive teeth. She hopes she appears to him like an angel: an angel of mercy. Because isn't she one? (Atwood 2015a: 69)

This seems a peculiar realization of Foucault's pity and ruthlessness amalgamation. Bringing mercy, Charmaine is the hand of oppressive power, and her partial unawareness, or supersession, of the role she plays makes it even more disturbing.

Special Procedure is also another example of Positron's ultra-capitalistic self-sufficiency, as well as a depiction of utopian thinking turning dystopian. As nothing can be wasted in this model of a new society, human bodies cannot be simply buried, either. Atwood reenters the cannibalistic idea that has already appeared in the form of secret burgers in The Year of the Flood. Wondering about the procedure, Charmaine speaks to herself:

What will happen to the body? Not cremation; that's a wasteful power draw. And no inmates in any form, dead or alive, depart through the gates of Consilience. She's wondered about organ harvesting, but wouldn't they want them brain-dead and on a drip rather than plain old dead, period? Surely the fresher the better, when it comes to organs. Protein-enriched livestock feed? Charmaine can't believe they'd do that, it wouldn't be respectful. But whatever happens, it's bound to be useful, and that's all she needs to know. There are some things it's better not to think about. (Atwood 2015a: 70)

Charmaine senses the brutal and unforgivable truth, but deliberately attempts to ignore it. Doing so, she struggles to place herself on the side of the oppressors (hence, the arguments that she uses to convince herself about her innocence). However, although she realizes that there are some questions that should not be asked, these deeply ethical enquiries continue to haunt the protagonist's thought; she wonders:

And what happened to the bodies, really? After the Procedures. She'd never asked; she must have known that it would be crossing a line. Is there even a cemetery in Consilience? Or Positron Prison? She's never seen one. (Atwood 2015a: 183)

Positron, then, proves to be a huge state-of-the-art company illegally trafficking organ transplants: those who voluntarily enter the system lose all their rights and become potential source of valuable body parts. In Atwood's view this works as a political metaphor of our digital and unsettled times; she states: "Digital technology has made it easier than ever to treat people like domesticated animals farmed for profit” (Atwood 2015b).

\section{Under our eye}

Commenting on the development of the western penal system and its interdependence with the entire western civilization, Michel Foucault notes in Discipline and Punish:

The old partners of the spectacle of punishment, the body and the blood, gave way. A new character came on the scene, masked. It was the end of a certain kind of tragedy; comedy began, with shadow play, faceless voices, impalpable entities. The apparatus of punitive justice must now bite into this bodiless reality. (1995: 16-17) 
In other words, our culture is the one which has understood that there are more important aspects of people's lives to punish and control than mere physicality: it is our most fundamental freedom that seems to be at stake. This idea has to be comprehended in more universal terms: ours is the culture of superficial and materialistic excess that masks political and social circumscription. Margaret Atwood perceives this even more dramatic shift to a deprivation of liberty that we may observe in the $21^{\text {st }}$ century in a similar way. In her 2015 essay she states:

Minus our freedom, we may find ourselves no safer; indeed we may be double-plus unfree, having
handed the keys to those who promised to be our defenders but who have become, perforce, our
jailers. A prison might be defined as any place you've been put into against your will and can't get
out of, and where you are entirely at the mercy of the authorities, whoever they may be. Are we
turning our entire society into a prison? If so, who are the inmates and who are the guards? And
who decides? (Atwood 2015b)

Atwood perceives this pattern of "double-plus unfree" as a delusion of real freedom. It is a very dangerous situation for all of us, since manipulated in a clever way, this ersatz of liberty may result in such a kind of enslavement, where we are not fully aware of it. We may simply settle for what is given to us by the authorities without questioning the mechanisms of power. Hence, she enters the territory of a penitentiary system seeing in it an alarmingly excellent metaphor of our times.

What is particularly interesting in this vision of the future is the fact that Atwood actually moves her attention away from the body to everything that transgresses it and is definitely more important than it. We may call it a set of universal and fundamental freedoms that define who we are. In the already cited article Atwood states: "Our governments now treat us like cattle - governed by fear, we have surrendered too many of our hard-won freedoms" (Atwood 2015b). We may also use here Foucault's insight when he writes about the machinery of punishment focused on our soul: "... since it is no longer the body, it must be the soul. The expiation that once rained down upon the body must be replaced by a punishment that acts in depth on the heart, the thoughts, the will, the inclinations" (1995: 16). Atwood's perfect prison realizes this postulate: the system obviously needs a human body, but it is even more interested in the immeasurable aspects of our identities. It feeds on our identities - a set of characteristics, rights, and urges that make who we really are — and turns us into chain links in a large machinery where we actually lose ourselves. The prison system as viewed by Atwood is also close to Foucault's diagnosis of the Panopticon, which - according to the French philosopher - resembles a machine that is used by the authorities to experiment with the tissue of the society, to change its citizens, to mold individuals the way that suits those in power (1995: 203).

Last but not least, the Positron project would not be that effective without the sophisticated monitoring procedures and tight surveillance performed by the management on the inmates. Describing the most fundamental assumptions of the Panopticon, Bentham notes: "the greater chance there is, of a given person's being at a given time actually under inspection, the more strong will be the persuasion - the more intense, if I may say so, the feeling, he has of his being so" (1995: 13). Bentham, then, realizes the significance of tight surveillance. Explaining and expanding this thought, Foucault adds: "The Panopticon is a machine for dissociating the see/being seen dyad: in the peripheric ring, one is totally seen, without ever seeing; in the central tower, one sees everything without ever being seen" (1995: 201-202). Obviously, in the case of the world created by Atwood in The Heart Goes Last, the methods of 
surveillance are more updated and technology-based. The representative of the management informs the inmates: "You all know the rules: phones are to be used for personal intercommunication with your friends and loved ones, but no more. We take boundaries very seriously here at Positron!" (Atwood 2015a: 82). And it is not only the telephone network that is used to monitor the individuals. Those in power know that the most productive way to control people is to create the atmosphere of being constantly watched, i.e. the atmosphere of the Panopticon: "the street is empty. Or it seems empty: no doubt there are eyes embedded everywhere - the lamppost, the fire hydrant. Because you can't see them doesn't mean they can't see you" (1995: 92). Commenting on the mechanisms of the Panopticon, Foucault notes: "Thanks to its mechanisms of observation, it gains in efficiency and in the ability to penetrate into men's behavior; knowledge follows the advances of power, discovering new objects of knowledge over all the surfaces on which power is exercised" (1995: 204). In other words, sophisticated methods and devices of monitoring are crucial for the authorities to exercise and maintain their power. And those methods and devises evolve with the passing of time, providing the authorities with newer and cleverer means of oppression.

\section{Freedom to, or freedom from}

The most important idea behind The Heart Goes Last is that, while focusing on the contemporary prison system, it is definitely about something more universal and closer to each of us. Stan, the male protagonist of the novel, realizes this recognition when he states: "A demonstration of power. What's been going on in the turbulent world outside the closed fishbowl of Consilience? No, not a fishbowl, because no one can see in" (Atwood 2015a: 119-120). Hence, it is all about power and the way we yield to it when the other alternative is to step out of our comfort zone and risk what we already have, no matter how illusionary and shaky that is. In her recent essay Atwood poses a number of important questions: "Should we choose «freedom from» or «freedom to»? The safe cage or the dangerous wild? Comfort, inertia and boredom, or activity, risk and peril?" (2015b). These questions asked in 2015 parallel Atwood's ideas expressed in her seminal The Handmaid's Tale as spoken by Aunt Lydia to a group of women just deprived of their most basic civil rights: "There is more than one kind of freedom... Freedom to and freedom from. In the days of anarchy, it was freedom to. Now you are being given freedom from. Don't underrate it" (1996: 34). This proves the gravity of such issues and their topicality. Are we really and unconditionally free, or do we delude ourselves with the phantasm of it? Do we live in a world or society in which we decide, or are we manipulated to believe so? Being unable to answer these questions in an unambiguous way, we find ourselves trapped in cages like those in prisons, at the authorities' full mercy. Foucault understands the tight relation between power and the Panopticon in the following way:

it does not matter who exercises power. Any individual, taken almost at random, can operate the machine: in the absence of the director, his family, his friends, his visitors, even his servants. Similarly, it does not matter what motive animates him: the curiosity of the indiscreet, the malice of a child, the thirst for knowledge of a philosopher who wishes to visit this museum of human nature, or the perversity of those who take pleasure in spying and punishing. The more numerous those anonymous and temporary observers are, the greater the risk for the inmate of being surprised and the greater his anxious awareness of being observed. The Panopticon is a marvelous machine which, whatever use one may wish to put it to, produces homogeneous effects of power. (1995: 202) 
Atwood seems to view the power structures in a similar way. Somehow answering the questions asked above, she declares: "If there's one thing we ought to know by now, it's that absolutist systems with no accountability and no checks and balances generate monstrous abuses of power. That seems to be an infallible rule" (2015b).

\section{Bibliography}

Alter Alexandra (2015), Margaret Atwood, Digital Deep-Diver, Writes The Heart Goes Last, "The New York Times”, 27 Sept. 2015, https:/www.nytimes.com/2015/09/28/books/margaretatwood-digital-deep-diver-writes-the-heart-goes-last.html [access: 7.07.2020].

Atwood Margaret (1996), The Handmaid's Tale, Vintage, London.

- (2015a), The Heart Goes Last, Bloomsbury, London.

- (2015b), We Are Double-plus Unfree, “The Guardian”, https://www.theguardian.com/books/2015/sep/18/margaret-atwood-we-are-double-plus-unfree [access: 7.07.2020].

Bentham Jeremy (1995), The Panopticon Writings, ed. Bozovic M., Verso, London.

Foucault Michel (1995), Discipline and Punish: The Birth of the Prison, trans. A. Sheridan, Vintage Books, New York.

Harrison M. John (2015), The Heart Goes Last by Margaret Atwood Review - Rewardingly Strange, "The Guardian", https://www.theguardian.com/books/2015/sep/23/the-heart-goes-last-margaret-atwood-review-novel [access: 7.07.2020].

Johnson Mat (2015), Margaret Atwood's The Heart Goes Last, “The New York Times”, https:// www.nytimes.com/2015/09/27/books/review/margaret-atwoods-the-heart-goes-last.html [access: 7.07.2020].

Keeler Emily M. (2015), Free Love and Free Will: Margaret Atwood on Her New Novel, "Nationalpost.com", https://nationalpost.com/entertainment/books/margaret-atwood-on-theheart-goes-last [access: 7.07.2020].

Lyall Sarah (2015), Review: Margaret Atwood's The Heart Goes Last Conjures a Kinky Dystopia, “The New York Times”, https://www.nytimes.com/2015/09/30/books/review-margaretatwoods-the-heart-goes-last-conjures-a-kinky-dystopia.html [access: 7.07.2020].

Orwell George (1987), Nineteen Eighty-Four, Penguin Books, London. 